\title{
HLA antigens and toxic reactions to sodium aurothiopropanol sulphonate and D-penicillamine in patients with rheumatoid arthritis
}

\author{
P PERRIER, ${ }^{1}$ C RAFFOUX, ${ }^{2}$ Ph THOMAS,${ }^{3} \mathrm{~J} \mathrm{~N}$ TAMISIER, ${ }^{3}$ \\ M BUSSON, ${ }^{2}$ A GAUCHER, ${ }^{4}$ AND F STREIFF ${ }^{1}$
}

From the ${ }^{1}$ Centre Régional de Transfusion Sanguine, 9-11 Rue Lionnois 54000 Nancy; ${ }^{2}$ Unité INSERM U93, Hôpital St Louis, Paris; ${ }^{3}$ Service de Rhumatologie, CHR Metz-Thionville, Hôpital Beauregard Thionville; ${ }^{4}$ Clinique de Rhumatologie, CHU Nancy-Vandoeuvre, France

SUMMARY One hundred and forty-one patients with rheumatoid arthritis treated with aurothiopropanol sulphonate or D-penicillamine, or both were examined for HLA antigens to investigate the genetic influence on the occurrence of different adverse reactions during therapy. All 13 patients possessing HLA-DR3 had toxic reactions. The relative risk for DR3 positives of developing skin eruptions or proteinuria was calculated to be 10.5 times and seven times respectively that of DR3 negatives. The incidence of DR7 antigen in 94 patients with toxic reactions was significantly decreased (11\% compared with $28 \%$ in controls) suggesting a protective role for this antigen.

Key words: drug intolerance, major histocompatibility complex, HLA-DR, proteinuria, immunogenetics, genetic predisposition.

Stastny, ${ }^{1}$ in 1978 , established that there is an association between classical or definite rheumatoid arthritis (RA), according to the American Rheumatism Association (ARA) criteria, and the HLA-DR4 antigen. A genetic predisposition to toxic reactions to sodium aurothiomalate and penicillamine therapy was suggested by Panayi, ${ }^{2}$ in the same year. In 1980 Wooley $^{3}$ showed that the development of proteinuria in patients treated with sodium aurothiomalate is associated with the presence of HLA-B8 and DR3 antigens but found no significant association between these HLA antigens and haematological complications of treatment with either drug or both drugs.

Our present study reports on 141 patients with RA and analyses the associations between HLA antigens and toxic reactions to sodium aurothiopropanol sulphonate and D-penicillamine.

\section{Patients and methods}

PATIENTS

One hundred and forty-one Caucasian patients (39

Accepted for publication 5 March 1985.

Correspondence to Dr P Perrier, Centre Régional de Transfusion Sanguine, 9-11 Rue Lionnois 54000 Nancy, France. male and 102 female) with classical or definite RA, according to the ARA criteria, with a mean age of 54.3 years (range 27-77) and living in the same country were studied. Patients were selected who had received gold salts or D-penicillamine treatment for at least six months.

The mean duration of disease when therapy was started was 7.6 years (range 7 months-27 years). Ninety-eight patients $(70 \%)$ were seropositive for rheumatoid factor (RF) and had a Rose-Waaler titre $>1 / 64$.

\section{DRUG ADMINISTRATION}

Eighty-seven patients had received only sodium aurothiopropanol sulphonate (Allochrysine) (30\% metal); the initial phase of the treatment consisted of 20 weekly injections up to a total dose of $1 \mathrm{~g} \mathrm{(12.5}$ $\mathrm{mg}, 25 \mathrm{mg}$, then weekly injections of $50 \mathrm{mg}$ ), and if the treatment was beneficial to the patient, without adverse reactions, he received $100 \mathrm{mg}$ monthly.

Thirty patients had received only D-penicillamine (Trolovol) $150 \mathrm{mg}$ daily during the first week, 300 $\mathrm{mg}$ daily for the next four weeks, $600 \mathrm{mg}$ daily for the following four weeks, and then $750-900 \mathrm{mg}$ daily. 
Table 1 Frequency (\%) of HLA-DR antigens in $R A$ patients and controls

\begin{tabular}{llll}
\hline $\begin{array}{l}\text { HLA-DR } \\
\text { antigens }\end{array}$ & $\begin{array}{l}\text { Patients } \\
(n=141)\end{array}$ & $\begin{array}{l}\text { Controls } \\
(n=254)\end{array}$ & $p$ \\
\hline DR1 & $20 \cdot 5$ & $12 \cdot 9$ & $\mathrm{NS}^{*}$ \\
DR2 & $24 \cdot 1$ & $32 \cdot 6$ & $\mathrm{NS}$ \\
DR3 & $9 \cdot 2$ & $20 \cdot 0$ & $<10^{-2}$ \\
DR4 & $45 \cdot 3$ & $24 \cdot 4$ & $<10^{-4}$ \\
DR5 & $16 \cdot 3$ & $31 \cdot 1$ & $<10^{-2}$ \\
DRw6 & $9 \cdot 2$ & $16 \cdot 1$ & $\mathrm{NS}$ \\
DR7 & $13 \cdot 4$ & $28 \cdot 7$ & $<10^{-3}$ \\
\hline
\end{tabular}

${ }^{*} \mathrm{NS}=$ not significant.

Twenty-four patients had received gold salts and D-penicillamine.

Toxic reactions were monitored by periodic urine analyses, blood counts, and regular physical examination. Patients without symptoms of toxicity for at least six months of treatment were scored as drugreaction negative.

\section{ADVERSE REACTIONS}

Forty-seven RA patients were free of symptoms of toxicity $(33 \%)$. Ninety-four RA patients presented one or more toxic reactions to gold salts (56 patients) or D-penicillamine (18 patients) or both drugs (20 patients). One hundred and twenty-four adverse reactions were observed: 57 cutaneous reactions (53 skin eruptions, two stomatitis, one pemphigus, one erythroderma); 34 proteinuria eight between 0.1 and $0.50 \mathrm{~g} /$ day, 23 more than $0.50 \mathrm{~g} /$ day, three nephrotic syndrome with proteinuria more than $3 \mathrm{~g}$ /day and serum albumin of less than $30 \mathrm{~g} / \mathrm{l}) ; 17$ haematological adverse reactions; nine thrombocytopenia (platelet count $\left.<100 \times 10^{9} / 1\right)$, five leucopenia (leucocyte count $<2 \cdot 5 \times 10^{9} / 1$ ), one eosinophilia (eosinophile count: $\left.2 \times 10^{9} / 1\right)$, two agranulocytosis; 16 other adverse

Table 2 Frequency (\%) of some HLA-A, B, DR antigens in $94 R A$ patients with toxic reactions

\begin{tabular}{|c|c|c|c|}
\hline $\begin{array}{l}\text { HLA } \\
\text { antigens }\end{array}$ & $\begin{array}{l}\text { Patients with } \\
\text { toxic reactions } \\
(n=94)\end{array}$ & Controls ${ }^{*}$ & $p$ \\
\hline A1 & $27 \cdot 6$ & $27 \cdot 7$ & NS ${ }^{\dagger}$ \\
\hline B8 & $23 \cdot 4$ & $17 \cdot 4$ & NS \\
\hline B12 & $23 \cdot 4$ & $28 \cdot 8$ & NS \\
\hline B27 & $13 \cdot 8$ & $8 \cdot 2$ & NS \\
\hline DR1 & $24 \cdot 4$ & 12.9 & NS \\
\hline DR2 & $19 \cdot 1$ & $32 \cdot 6$ & $<0.05$ \\
\hline DR3 & $13 \cdot 8$ & $20 \cdot 0$ & NS \\
\hline DR4 & 41.4 & $24 \cdot 4$ & $<10^{-2}$ \\
\hline DR7 & $11 \cdot 7$ & $28 \cdot 7$ & $<10^{-3}$ \\
\hline
\end{tabular}

*1097 Controls for HLA-A, B; 254 controls for HLA-DR. $+\mathrm{NS}=$ not significant. reactions: one myasthenia gravis, one D-penicillamine induced lupus (antinuclear antibody $\frac{}{\omega}$. detected at a titre of $1 / 2500$ with a homogeneous pattern), one polyneuropathy of the Guillain-Barre of type, two cholestatic hepatitis, three nausea, 0 vomiting, four ageusia, and four hyperthermia.

HLA ANTIGENS

The HLA typing was performed by the microlymphocytotoxicity technique (NIH). Ninety alloantisera defined 13 HLA-A antigens (A1, A2, A3, A9. (Aw23-Aw24), A10 (A25-A26), A11, A28, A19. 2, $\vec{\omega}$ Aw32) and 15 HLA-B antigens (B5, B7, B8, B12, B13, B14, B15, Bw16, B17, B18, Bw21, Bw22, B27, Bw35, B40). Fifty-eight local and exchanged alloantisera defined seven alleles - DR1 to DR7.

For HLA-DR antigen testing we used a $B_{\sigma}^{\circ}$ lymphocyte preparation enriched by elimination of ${ }_{-}^{N}$ T lymphocytes rosetted with AET-treated sheep redo blood cells.

The control panel consisted of 1097 healthy bloodes donors typed for HLA-A, B antigens and 254 healthy blood donors typed for HLA-DR antigens $\triangle$ all living in the same country as the patients.

STATISTICAL ANALYSIS

○े $\overrightarrow{0}$

The $\chi^{2}$ test with Yates's correction or Fisher's ex\&etco test was used for statistical analysis, whichever applicable. A p value of less than 0.05 was cont-o sidered to be statistically significant. Relative risk (RR) values were calculated by the classical Woolfô method.

\section{Results}

The antigenic frequency of DR4 in these 141 RA patients was $45 \%$, whereas it was $24 \%$ in the control healthy population $\left(\mathrm{p}<10^{-4}\right)$. The relative risk for DR4 positives of developing RA was calculated to be 2.5 times that of DR4 negatives (Table 1).

As shown in Tables 2 and 3 DR3 antigen was absent in 47 patients without toxic reactions, 3 whereas 13 out of 94 patients $(13.8 \%)$ with toxico reactions carried the DR3 antigen $\left(p<10^{-2}\right)$. However, this antigenic frequency was not signifi-o cantly different from the DR3 frequency among 254 . controls $(20 \%)$.

The frequency of DR7 antigen was significantlyn decreased in 94 RA patients with toxic reactions N $(11.7 \%)$ compared with controls $\left(28.7 \%, p<10^{-3}\right)$. $\sigma$

The statistical analysis showed a significant association between the presence of $\mathrm{B} 8$ and DR3 antigens and proteinuria (Table 4). The relatives risk of proteinuria during gold or D-penicillamine therapy was increased seven times in patients witho the DR3 antigen. 
Table 3 Frequency (\%) of some $H L A-A, B, D R$ antigens in $47 R A$ patients without toxic reactions

\begin{tabular}{|c|c|c|c|}
\hline $\begin{array}{l}H L A \\
\text { antigens }\end{array}$ & $\begin{array}{l}\text { Patients without } \\
\text { toxic reactions } \\
(n=47)\end{array}$ & Controls* & $p$ \\
\hline A1 & $27 \cdot 6$ & $27 \cdot 7$ & NS + \\
\hline B8 & $8 \cdot 5$ & $17 \cdot 4$ & NS \\
\hline B12 & $31 \cdot 9$ & $28 \cdot 8$ & NS \\
\hline B27 & $8 \cdot 5$ & $8 \cdot 2$ & NS \\
\hline DR1 & $12 \cdot 0$ & $12 \cdot 9$ & NS \\
\hline DR2 & $34 \cdot 0$ & $32 \cdot 6$ & NS \\
\hline DR3 & $0 \cdot 0$ & $20 \cdot 0$ & $<10^{-3}$ \\
\hline DR4 & $53 \cdot 2$ & $24 \cdot 4$ & $<10^{-4}$ \\
\hline DR7 & $17 \cdot 0$ & $28 \cdot 7$ & NS \\
\hline
\end{tabular}

* 1097 controls for HLA-A, B; 254 controls for HLA-DR. $\dagger \mathrm{NS}=$ not significant.

A positive correlation between DR3 antigen (Table 5) and mucocutaneous reactions was found $\left(\mathrm{p}<10^{-3}\right.$ with relative risk of $\left.10 \cdot 5\right)$.

Nine severe cases of rapid thrombocytopenia were recorded in eight patients. One patient developed thrombocytopenia successively during gold and D-penicillamine therapy. Of these eight RA patients, three were B8 or DR3 positive.

\section{Discussion}

Our results confirm the increased frequency of HLA-DR4 in RA patients compared with the control population $(45 \% \quad v 24 \%)$ as originally reported by Stastny. ${ }^{1}$ We noted a decreased frequency of DR2, DR3, DR5, and DR7 antigens in 220 European Caucasian RA patients in accordance with the 8th Histocompatibility Workshop. ${ }^{4}$

Several studies have reported on associations between HLA antigens, particularly of the DR locus, and the occurrence of side effects due to gold or D-penicillamine, or both.

HLA-DR3 was found to be increased in RA patients with intolerance to sodium aurothiomalate and/or D-penicillamine which included proteinuria $^{36-8}$ and mucocutaneous reactions. ${ }^{2} 7$ Several

Table 4 Distribution (\%) of some HLA antigens in RA patients with and without proteinuria

\begin{tabular}{llll}
\hline $\begin{array}{l}\text { HLA } \\
\text { antigens }\end{array}$ & $\begin{array}{l}\text { Patients with } \\
\text { proteinuria } \\
(n=32)\end{array}$ & $\begin{array}{l}\text { Patients without } \\
\text { proteinuria } \\
(n=109)\end{array}$ & $p$ \\
\hline A1 & 34 & 26 & $\mathrm{NS}^{*}$ \\
B8 & 34 & 14 & $<10^{-2}$ \\
DR3 & 25 & 5 & $<10^{-3}$ \\
\hline
\end{tabular}

${ }^{*} \mathrm{NS}=$ not significant.
Table 5 Distribution (\%) of some HLA antigens in RA patients with and without mucocutaneous reactions

\begin{tabular}{llll}
\hline $\begin{array}{l}\text { HLA } \\
\text { antigens }\end{array}$ & $\begin{array}{l}\text { Patients with } \\
\text { mucocutaneous } \\
\text { reactions } \\
(n=55)\end{array}$ & $\begin{array}{l}\text { Patients without } \\
\text { mucocutaneous } \\
\text { reactions } \\
(n=86)\end{array}$ & $p$ \\
\hline A1 & 32.7 & $24 \cdot 4$ & $\mathrm{NS}^{*}$ \\
B8 & $21 \cdot 8$ & $16 \cdot 2$ & $\mathrm{NS}$ \\
Bw35 & $18 \cdot 1$ & $22 \cdot 0$ & $\mathrm{NS}$ \\
DR1 & $27 \cdot 2$ & $16 \cdot 2$ & $\mathrm{NS}$ \\
DR3 & $20 \cdot 0$ & $2 \cdot 3$ & $<10^{-3}$ \\
\hline
\end{tabular}

*NS=not significant

other studies, however, have failed to confirm the relationship between HLA markers and toxic manifestations during treatment with sodium aurothiomalate or D-penicillamine. ${ }^{13} 14$

Two studies have shown an association between HLA-DR 3 positivity and proteinuria ${ }^{5}$ or cutaneous reactions ${ }^{10}$ in aurothioglucose treated patients with RA.

Two other studies ${ }^{9} 18$ have shown conflicting results with respect to correlation between proteinuria due to sodium aurothiopropanol sulphonate and DR3 antigen.

Our data indicate that RA patients carrying the DR3 antigen seem to be at an increased risk of developing proteinuria and/or mucocutaneous reactions to sodium aurothiopropanol sulphonate or D-penicillamine, or both. All 13 patients carrying the DR3 antigen had toxic reactions. This association was very marked among the patients who developed proteinuria during the treatment but without correlation with the amount of proteinuria, confirming the study of Gran et al. ${ }^{6}$

Our data relating to thrombocytopenia do not permit a clear cut conclusion to be drawn owing to the limited number of cases available. However, other studies ${ }^{711} 12$ favour a correlation between aurothiomalate induced thrombocytopenia and HLA-DR3 and B8. Coblyn ${ }^{11}$ and Adachi ${ }^{12}$ have postulated that gold induced thrombocytopenia is immune mediated, in association with HLA-B8, DR3, with the production of platelet associated IgG leading to peripheral platelet destruction.

In contrast, DR2 and DR7 antigens were less prevalent among RA patients with toxic reactions than among patients without toxic reactions or controls, suggesting that DR2 and DR7 antigens have a protective effect, which is in agreement with several studies. ${ }^{6} 81516$

However, Panayi ${ }^{2}$ reported a significant association between DR2 and toxic reactions to sodium aurothiomalate and penicillamine. 
Ford $^{17}$ and Dequeker ${ }^{18}$ gave several explanations for these conflicting results: bias in patient selection, too small a number of patients, different preparations of gold, different definition of the non-toxic group.

Our results confirm that DR3 positivity is related to toxicity to gold and D-penicillamine. However, Van Riel et al. ${ }^{10}$ have shown that DR3 positivity is also related to favourable clinical response in 25 aurothioglucose treated patients.

All these data provide evidence that HLA typing is of considerable scientific interest in the understanding of the mechanisms of drug toxicity but fails to select RA patients for gold or D-penicillamine treatment. Therefore, periodic urine analyses, blood counts, and physical examination are the better guides to therapy.

\section{References}

1 Stastny P. Association of the B cell alloantigen DRw4 with rheumatoid arthritis. $N$ Engl J Med 1978; 298: 869-71.

2 Panayi G S, Wooley P, Batchelor J R. Genetic basis of rheumatoid disease: HLA antigens, disease manifestations, and toxic reactions to drugs. $\mathrm{Br}$ Med $J$ 1978; ii: 1326-8.

3 Wooley P H, Griffin J, Panayi G S, Batchelor J R, Welsh K I, Gibson T J. HLA-DR antigens and toxic reaction to sodium aurothiomalate and D-penicillamine in patients with rheumatoid arthritis. N Engl J Med 1980; 303: 300-2.

4 Stastny P. Joint report. Rheumatoid arthritis. In: Terasaki P I, ed. Histocompatibility testing. Los Angeles: UCLA Tissue Typing Lab., 1980: 681-6.

5 Speerstra F, Reekers P, van de Putte L B A, Vandenbroucke J P, Rasker J J, de Rooij D. HLA-DR antigens and proteinuria induced by aurothioglucose and D-penicillamine in patients with rheumatoid arthritis. J Rheumatol 1983; 10: 948-53.
6 Gran J T, Husby G. Thorsby E. HLA-DR antigens and gold toxicity. Ann Rheum Dis 1983; 42: 63-6.

7 Bensen W G, Moore N, Tugwell P, D'Souza M, Singal D P. HLA antigens and toxic reactions to sodium aurothiomalate in patients with rheumatoid arthritis. J Rheumatol 1984; 11: 358-61.

8 Nusslein H G, Jahn H, Losch G, Guggenmoos-Holzmann I, Leibold W, Kalden J R. Association of HLA-Bw35 witho mucocutaneous lesions in rheumatoid patients undergoing $\mathscr{\mathbb { D }}$ sodium aurothiomalate therapy. Arthritis Rheum 1984; 27:으 833-6.

9 Bardin T, Dryll A, Debeyre N, et al. HLA system and sideeffects of gold salts and D-penicillamine treatment of rheuma-, toid arthritis. Ann Rheum Dis 1982; 41: 599-601.

10 Van Riel P L C M, Reekers P, van de Putte L B A, Gribnauc F W J. Association of HLA antigens, toxic reactions and therapeutic response to auranofin and aurothioglucose in patients with rheumatoid arthritis. Tissue Antigens 1983; 22:$194-9$.

11 Coblyn J S, Weinblatt M, Holdsworth D, Glass D. Goldco induced thrombocytopenia. A clinical and immunogenetic studyos of 23 patients. Ann Intern Med 1981; 95: 178-81.

12 Adachi J D, Bensen W G, Singal D P, Powers P J. Goldo induced thrombocytopenia: platelet associated IgG and $\mathrm{HLA}^{-}$ typing in three patients. $J$ Rheumatol 1984; 11: 355-7.

13 Karr R W, Rodey G E, Lee T, Schwartz B D. Association of HLA-DRw4 with rheumatoid arthritis in black and whiteo patients. Arthritis Rheum 1980; 23: 1241-5.

14 Majoos F L, Klemp P, Meyers O L, Briggs B. Gold therapy in rheumatoid arthritis. S Afr Med J 1981; 59: 971-4.

15 Chales G, Fauchet R, Pawlotsky Y, et al. Les déterminants HLA-DR dans les rhumatismes inflammatoires chroniques. Reve Rhum Mal Osteoartic 1983; 50: 525-31.

16 Repice M M, Radvany R M, Schmidt F R. HLA-A, -B, -C -DR locus antigens and gold toxicity in rheumatoid arthrit [Abstract]. Clin Res 1979: 647A.

17 Ford $P$ M. HLA antigens and drug toxicity in rheumatoide arthritis. J Rheumatol 1984; 11: 259-61.

18 Dequeker J, Van Wanghe P, Verdickt W. A systematic survey of HLA-A, B, C and D antigens and drug toxicity ino rheumatoid arthritis. J Rheumatol 1984; 11: 282-6. 